Cahiers

d'ethnomusicologie

\section{Cahiers d'ethnomusicologie}

Anciennement Cahiers de musiques traditionnelles

6 | 1993

Polyphonies

\title{
Rujindiri maitre de l'inanga, musique de l'ancienne cour du Rwanda
}

Fonti musicali, Traditions du monde et Centre Ethnomusicologique Paul

Collaer. 1990

Didier Demolin

\section{(2) OpenEdition}

Journals

Édition électronique

URL : http://journals.openedition.org/ethnomusicologie/1517

ISSN : 2235-7688

Éditeur

ADEM - Ateliers d'ethnomusicologie

Édition imprimée

Date de publication : 31 octobre 1993

Pagination : 243-244

ISBN : 2-8257-0485-7

ISSN : 1662-372X

\section{Référence électronique}

Didier Demolin, «Rujindiri maître de l'inanga, musique de l'ancienne cour du Rwanda », Cahiers

d'ethnomusicologie [En ligne], 6 | 1993, mis en ligne le 02 janvier 2012, consulté le 19 avril 2019. URL :

http://journals.openedition.org/ethnomusicologie/1517

Ce document a été généré automatiquement le 19 avril 2019

Tous droits réservés 


\title{
Rujindiri maître de l'inanga, musique de l'ancienne cour du Rwanda
}

\author{
Fonti musicali, Traditions du monde et Centre Ethnomusicologique Paul \\ Collaer. 1990
}

Didier Demolin

\section{RÉFÉRENCE}

Rujindiri maître de l'inanga, musique de l'ancienne cour du Rwanda, Enregistrements, textes et photos de Jos Gansemans. Notices en néerlandais, français et anglais. Fonti musicali, Traditions du monde et Centre Ethnomusicologique Paul Collaer. 1990. 1 CD Fonti musicali FMD 186. Durée totale : 61'35".

La publication de ce disque est un événement pour les amateurs de musique traditionnelle de l'Afrique Centrale, en particulier pour ceux qui apprécient la musique de la région des grands lacs (Rwanda, Burundi, Ouganda et l'est du Zaïre). C'est en effet la première fois, à notre connaissance, qu'une monographie est consacrée à l'art traditionnel de la cithare inanga, appelée aussi cithare en "forme de bouclier». Des enregistrements de musiciens du Burundi, de l'Ouganda et même quelques morceaux de Rujindiri et d'autres musiciens rwandais avaient déjà été publiés en disque (on citera entre autres: Burundi musiques traditionnelles, Ocora C559003; Evalisto Muyinda, PAN 2003CD et l'Anthologie de la musique traditionnelle du Rwanda, vol 1, musique instrumentale, Alpha 5023), mais jamais la musique d'un seul musicien n'avait fait l'objet d'une telle publication. Rujindiri était avec Sebatunzi un des deux grands musiciens de la tradition dont il existe des enregistrements. La musique de ce disque a été enregistrée au Rwanda vers le milieu des années septante par Jos Gansemans du Musée Royal de l'Afrique Centrale de Tervuren. Rujindiri, qui séjourna à la cour de deux des trois derniers rois ( mwami) du Rwanda, Musinga et Rudahigwa, continua d'exercer son art bien après l'avènement de la république dans son pays. A entendre la sélection que nous propose Jos Gansemans, on ne peut que s'en féliciter. 
2 Le répertoire traditionnel de l'inanga était exécuté par un chanteur instrumentiste qui s'accompagnait à la cithare pour vanter, dans un langage poétique, les hauts faits de la vie des rois et de leur cour. Cette musique souvent narrative, dans laquelle l'inanga jouait pour l'essentiel un rôle d'accompagnateur, était cependant transcendée lorsqu'elle accompagnait de la poésie ou lorsqu'elle était jouée par des musiciens exceptionnels. L'art complexe et subtil de Rujindiri confère à l'inanga une noblesse qui ne se rencontre plus guère de nos jours dans le jeu de cet instrument. Dans beaucoup de ses chants, Rujindiri, dont la mère était Twa, est accompagné d'un ou de deux autres chanteurs Twa, Semahe son beau-frère et Nyirashirambe. Au temps de la royauté, les Pygmées Twa étaient présents à la cour du mwami où leurs qualités de musiciens étaient très appréciées. Dans un tel contexte, l'importance accordée par Rujindiri à la voix ne parait pas surprenante. La majorité des chants du disque ont un caractère hétérophonique et polyphonique qui rappelle, sans conteste, la musique vocale des Twa du Rwanda. Seuls trois morceaux sont chantés en solo; il s'agit d'un vieux chant historique qui reflète sans doute assez bien le style de la musique de cour (plage 2) et de deux poèmes d'un style assez particulier (plages 3 et 10). La richesse du tissu vocal peut sembler contraster avec le jeu de l'inanga, fait la plupart du temps de petites formules mélodiques servant de soubassement au chant. Il ne faut cependant pas s'y tromper, car le jeu d'inanga de Rujindiri ne se limite pas exclusivement à un rôle d'accompagnement de la voix. Entre les strophes des chants, de courts interludes instrumentaux permettent au musicien de développer le jeu de l'instrument et ainsi de le faire sortir de son rôle d'accompagnateur de la voix.

3 Si les chants qui composent ce disque sont tous le reflet de la musique de cour, ils ne sont pas tous formés sur un modèle identique. Certains d'entre eux, Mureke (plage 1), Nyangezi (plage 7) et Impunga (plage 11) sont des versions, exécutées à l'inanga, d'un poème guerrier, d'un chant Twa et d'une berceuse, ce qui témoigne de la souplesse d'exécution et de l'imagination de Rujindiri. La plupart des autres chants (plages $2,4,5,6,8,9,12$ ) sont plus strictement des chants de cour et reflètent la vie et l'histoire des rois du Rwanda, certains d'entre eux étant par ailleurs forts anciens, puisque leur composition remonte au XVIIIe siècle.

Enfin, deux des chants, Kamujwara (plage 3) et Cyandari (plage 10), sont basés sur des textes d'un des trois grands genres de la poésie traditionnelle, les ibyivugo. Ces poèmes de quelques vers, assez courts, étaient récités sans interruption, sur un débit passablement rapide, pour vanter les mérites d'une personne importante ou, le plus souvent, de soimême. Jos Gansemans note dans son commentaire que, selon certains de ses informateurs, ces ibyivugo pourraient être à l'origine de la musique d'inanga. D'abord récités et accompagnés à la cithare, les textes auraient ensuite été dotés d'une mélodie. A l'écoute de ces deux morceaux, on peut se demander s'il ne s'agit pas simplement de la transposition de la mélodie de la voix parlée (le kinyarwanda est une langue tonale) en chant narratif. Jos Gansemans fait encore remarquer que cette possibilité de chanter ou de déclamer les poèmes se rencontre aussi dans les autres grands genres poétiques, la poésie pastorale amahamba ou amazina y'inka et la poésie dynastique ibisigo. Quoi qu'il en soit, cette remarque permet d'avoir une idée du degré de raffinement que la tradition musicale rwandaise avait atteint avec des musiciens comme Rujindiri, qui étaient capables de s'adapter au cadre assez strict et à la métrique complexe et rigoureuse de la poésie traditionnelle, tout en marquant cette musique de leur propre personnalité.

Ces enregistrements réalisés, il y a bientôt vingt ans, présentent ici et là des petits défauts techniques, mais il s'agit d'un détail mineur qui n'altère en aucun cas l'écoute de ce joyau 
de la tradition rwandaise. Il reste à espérer que cette publication incitera d'autres éditeurs et chercheurs à consacrer des monographies à des musiciens et à des instruments particuliers de cette région ou d'ailleurs en Afrique. On peut, par exemple, rêver d'un disque consacré à l'autre grand joueur d'inanga du Rwanda, Sebatunzi... 